\title{
PROCESSOS GEOCRIOGÊNICOS QUATERNÁRIOS NAS CIMEIRAS DA MANTIQUEIRA, COM CONSIDERAÇÕES CLIMÁTICAS
}

\author{
May Christine MODENESI-GAUTTIERI \\ Lucí Hidalgo NUNES
}

\author{
RESUMO
}

Possíveis efeitos de eventos tipo El Niño nos climas pretéritos das cimeiras da Mantiqueira são aqui considerados, a partir de evidências paleoclimáticas e dados da análise do clima atual dos planaltos de Campos do Jordão e Itatiaia. Um aparente paralelismo entre o comportamento atual do clima e as evidências paleoclimáticas parece reforçar as possibilidades de maior interferência dos processos geocriogênicos na evolução quaternária do planalto do Itatiaia.

\section{ABSTRACT}

Possible effects of El Niño-like events on the past climates of the Mantiqueira highlands are discussed considering paleoclimatic data and analysis of the present climate of Campos do Jordão and Itatiaia. An apparent parallelism between the present behavior of the climate and paleoclimatic evidences seems to reinforce the possibilities of greater interference of geocryogenic processes in the Quaternary evolution of the Itatiaia plateau.

\section{INTRODUÇÃO}

A compartimentação predominantemente tectônica da fachada atlântica do Brasil de Sudeste resulta da reativação, no Eoceno, das antigas zonas de cizalhamento Brasiliano-Panafricanas; falhamentos normais deram origem ao rift continental (ALMEIDA, 1976; RICCOMINI, 1989) e às feições dominantes do sudeste do Brasil: horst da Serra do Mar, semi-horst da Mantiqueira e graben do Vale do Paraíba. Soerguimentos pleistocênicos acentuaram a diferença de altitude entre os compartimentos, elevaram a Serra da Mantiqueira a mais de $2.000 \mathrm{~m}$ e determinaram uma evolução quaternária sob climas tropicais de altitude, menos quentes. Nos planaltos de Campos de Jordão e Itatiaia, situados na borda oriental da Mantiqueira (fig. 1), desenvolveu-se um sistema de paisagem de montanha tropical - os altos campos - nitidamente diferenciado dos mares de morros florestados (AB'SÁBER, 1969) das áreas mais baixas circunjacentes.

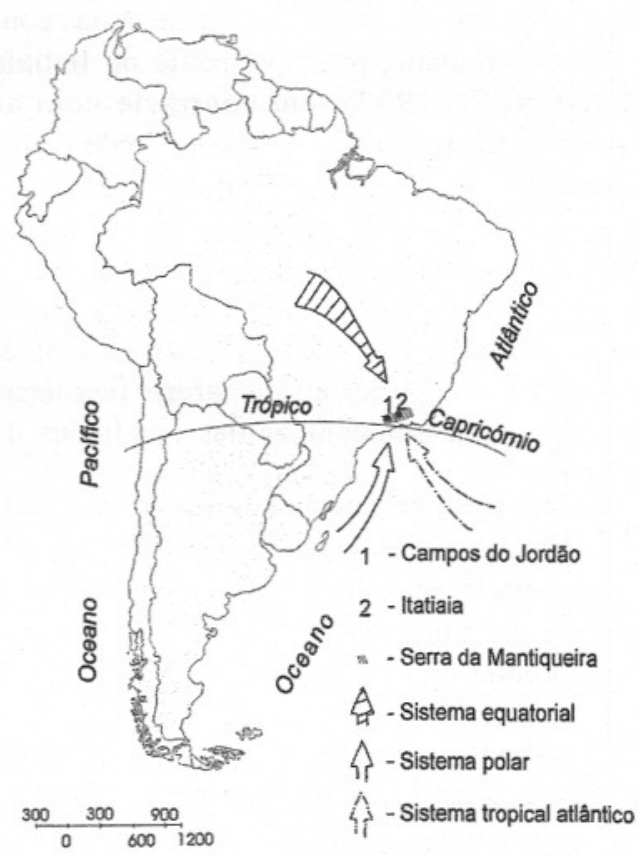

FIGURA 1 - Localização das cimeiras da borda oriental da Serra da Mantiqueira e fluxos atmosféricos atuantes. 
A área típica do planalto cristalino de Campos do Jordão tem aproximadamente $810 \mathrm{~km}^{2}$, altitudes máximas de $2.050 \mathrm{~m}$ e topos subnivelados, degradados e desdobrados em níveis erosivos (MODENESI, 1988); suas bordas escarpadas formam o segundo grande conjunto de escarpas do Brasil oriental, com o dobro da altitude da Serra do Mar. O maciço alcalino do Itatiaia eleva-se sobre os altos platôs da Mantiqueira, com área aproximada de $220 \mathrm{~km}^{2}$ e altitudes de até $2.778 \mathrm{~m}$ (Agulhas Negras). Predomina, entretanto, um relevo de menor amplitude $(2.300-2.500 \mathrm{~m})$, que caracteriza a parte central do maciço, conhecida como planalto.

A evolução pleistocênica dos dois planaltos é marcada por recuo acentuado das encostas, provavelmente relacionado a uma combinação de processos controlados pelo clima (movimentos de massa em Campos do Jordão e frost weathering em Itatiaia) e por reativações tectônicas. No Pleistoceno Terminal e Holoceno ocorreram eventos de coluviação, com menor capacidade erosiva e controle tectônico menos nítido, sendo que os registros sedimentares das baixas vertentes evidenciam mudança de processos e diminuição da atividade morfodinâmica (MODENESI, 1988; MODENESI-GAUTTIERI \& TOLEDO, 1996).

A evolução holocênica das cimeiras da Mantiqueira sugere maior permanência das condições de umidade, principalmente no Itatiaia (MODENESI, 1992), em contraste com as depressões interplanálticas vizinhas, onde houve intercalação de climas subquentes e mais secos. Em Campos do Jordão, descontinuidades encontradas nos depósitos de colúvio e de depressões turfosas (MODENESI, 1983; 1988) e dados palinológicos preliminares (MODENESI \& MELHEM, 1992) permitem inferir pequenas variações intra-holocênicas das condições de umidade.

A possível interferência de fenômenos periglaciais quaternários nas áreas mais elevadas da Mantiqueira foi levantada por DE MARTONNE (1940) e discutida, posteriormente, por vários autores (entre outros, SILVEIRA, 1942; BROCHU, 1957; MACAR, 1957; AB'SÁBER \& BERNARDES, 1958), que atribuíram algumas das formas e depósitos do planalto do Itatiaia à ação de processos periglaciais e, mesmo, glaciais. Evidências de ações periglaciais pretéritas foram também apontadas no planalto de Campos do Jordão (RAYNAL, 1957; LEH-
MAN, 1960). Mais recentemente, MODENESI (1992) e CLAPPERTON (1993) reconheceram a importância dos processos geocriogênicos na formação dos depósitos de vertente e na elaboração da paisagem do Itatiaia.

Certamente, durante as fases frias do Pleistoceno, temperaturas sensivelmente mais baixas que as atuais - um resfriamento regional de 4 a $6^{\circ} \mathrm{C}$ na última glaciação (CLIMAP, 1976; 1981) seria responsável por médias anuais de 7 a $5^{\circ} \mathrm{C}$ em Itatiaia e de 8 a $10^{\circ} \mathrm{C}$ em Campos do Jordão - aumentaram a incidência de processos geocriogênicos nos altiplanos do Sudeste. No Itatiaia, algumas formas de relevo e depósitos de textura muito grossa podem ser associados à ação desses processos (MODENESI-GAUTTIERI \& TOLEDO, 1996).

Neste trabalho, a ocorrência de condições quaternárias favoráveis à ação de processos geocriogênicos nas terras altas do Brasil de Sudeste é considerada a partir das evidências paleoclimáticas e de dados da análise do clima atual, inclusive da interferência do El Niño Oscilação Sul (ENOS) nos padrões habituais do clima dos planaltos de Campos do Jordão e Itatiaia.

As evidências paleoclimáticas foram inferidas de estudos geomorfológicos - com ênfase nas relações entre morfogênese, sedimentação, intemperismo e pedogênese (MODENESI, 1983, 1988, 1992; MODENESI \& TOLEDO, 1996) - e da interpretação paleoecológica preliminar de dados palinológicos (MODENESI \& MELHEM, 1986, 1992) dos planaltos de Campos do Jordão e Itatiaia.

$\mathrm{Na}$ análise do clima atual foi considerada a interferência das fases quente (EI Niño) e fria (La Niña) do ENOS nas anomalias anuais e mensais de chuva, geada, e temperatura (compensada, máxima e mínima), calculadas a partir dos desvios das séries históricas. A variação espacial da temperatura e da pluviosidade, que se verifica da borda sudeste do planalto de Campos do Jordão para o interior de Minas (MODENESI, 1988), orientou a escolha dos postos.

\section{FEIÇÕES GEOCRIOGÊNICAS NAS CIMEIRAS DA MANTIQUEIRA}

As hipóteses de glaciação quaternária no maciço do Itatiaia sempre foram motivo de controvérsia. Blocos e matacões, em situações diversas de deposição, distribuem-se por todos os setores das vertentes (PENALVA, 1967; 
MODENESI, 1992), sem apresentar marcas de ação glacial (CLAPPERTON, 1993). Vales e circos glaciais, morainas e outros depósitos reconhecidos como testemunhos de uma glaciação de montanha pleistocênica podem ter explicações alternativas. Por exemplo, os perfis de velhos vales, identificados por AB'SÁBER \& BERNARDES (1958) como vales glaciais dissecados, poderiam ter origem em períodos diferenciados de levantamento do planalto. Trata-se de restos de vales em $U$, elaborados em períodos de maior estabilidade, com setores inferiores em $\mathrm{V}$, originados por levantamentos subseqüentes (MODENESI, 1992). Os depósitos de matacões, encontrados no sopé do maciço e interpretados (EBERT, 1960) como sedimentos glaciais (boulder clay) da penúltima glaciação, foram tentativamente explicados por algum evento maior de rock avalanche (CLAPPERTON, 1993), possivelmente do Holoceno Inferior. Da mesma forma depósitos de solifluxão identificados em Campos do Jordão próximo do Itapeva, sobre gnaisses muito alterados (LEHMANN, 1960 ), seriam produtos de pequena movimentação, vertente abaixo, dos metaconglomerados alterados (MODENESI, 1988).

No entanto, existe pouca dúvida sobre a ocorrência dos processos geocriogênicos quaternários nas cimeiras da Mantiqueira, principalmente no Itatiaia (CLAPPERTON, 1993).

Em Campos do Jordão, pequenos clastos lamelares encontrados nas linhas de pedras (stone lines), principalmente acima de $1.800 \mathrm{~m}$, parecem constituir a única evidência de atividades geocriogênicas passadas. Estes clastos seriam produto de fragmentação, por gelifração, das crostas de gibbsita que recobrem a superficie da rocha alterada, provavelmente expostas durante os climas mais frios e secos do fim do Pleistoceno (MODENESI, 1988).

No Itatiaia, topos de interflúvio de aspecto ruiniforme (tor-like), paredões de rocha nua (free faces) e vertentes rochosas têm sido freqüentemente comparados com feições de áreas de clima frio (fig. 2). Mas as principais evidências da ação de processos geocriogênicos quaternários são os depósitos de textura grossa das vertentes médias do planalto (MODENESI, 1989, 1992; MODENESI-GAUTTIERI \& TOLEDO, 1996). Trata-se de uma série de registros: (1) talus e concentrações lineares de blocos e matacões (stone streams), certamente mais antigos do que o Pleistoceno Superior, suspensos acima das várzeas atuais e, com freqüência, fossilizados pela vegetação (fig. 3); (2) depósitos de fragmentos de rocha, achatados e angulosos, soltos, sem matriz e com acamamen- to incipiente, com características de velhos depósitos de montanhas de clima frio (screes), enterrados por colúvios (fig. 4); (3) níveis de concentração de pequenos clastos angulosos e pouco alterados no interior dos colúvios holocênicos, caracterizados por superposição complexa de horizontes húmicos (fig. 5).

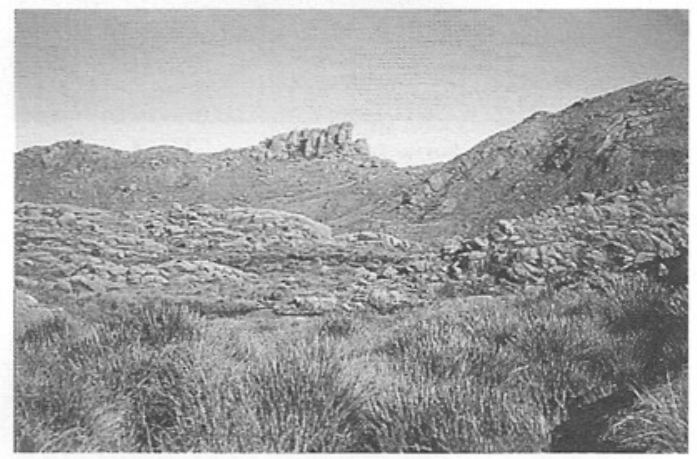

FIGURA 2 - As Prateleiras, exemplo de topografia ruiniforme (tor), provavelmente relacionada à ação de processos geocriogênicos sobre as rochas alcalinas muito diaclasadas do planalto do itatiaia.

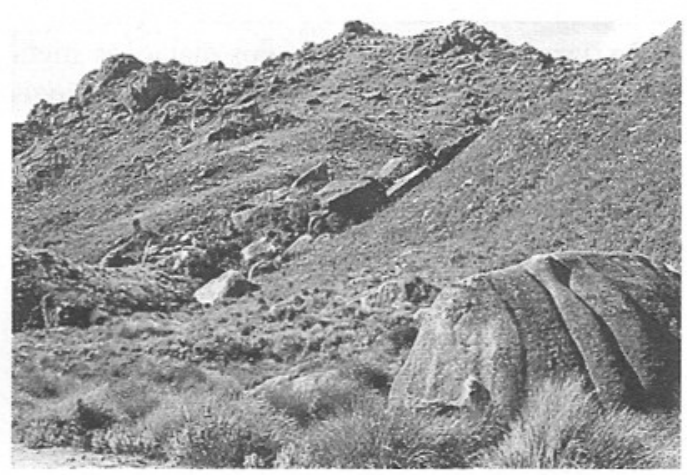

FIGURA 3 - Parte frontal das concentrações lineares de blocos e matacões (stone streams), suspensa sobre a várzea do ribeirão das Flores (Itatiaia).

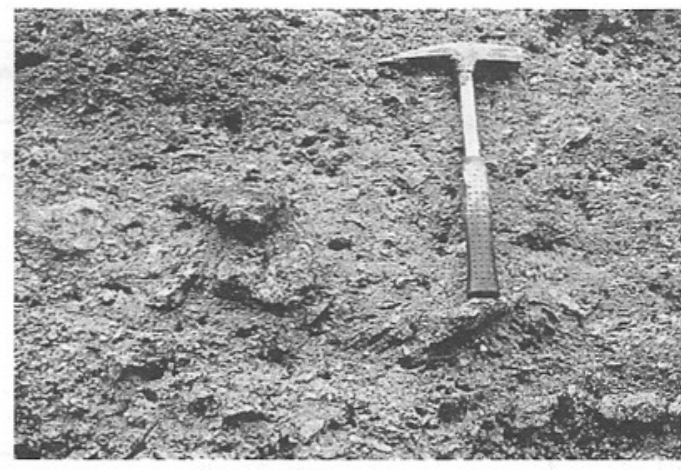

FIGURA 4 - Depósito de seixos e blocos (achatados, angulosos e sem matriz) encontrado sob os colúvios da borda noroeste do planalto do Itatiaia. As características de depósito de vertente de montanhas de clima frio (scree) indicam ação de processos geocriogênicos. 


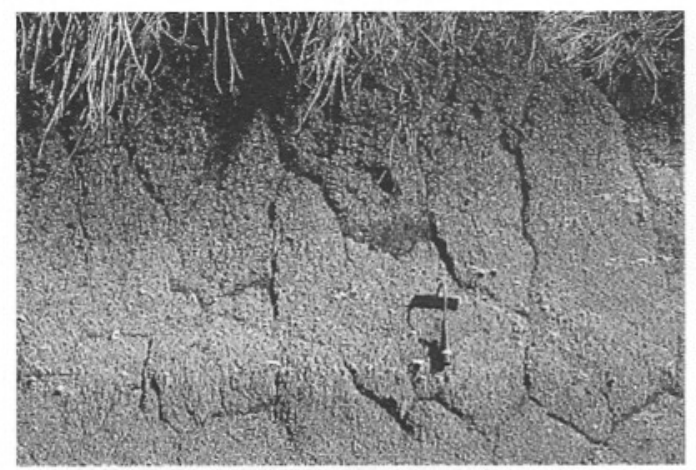

FIGURA 5 - Colúvios mais recentes do planalto do Itatiaia. Os níveis de concentração de grânulos e pequenos seixos, angulosos e pouco alterados, testemunhariam fases intra-holocênicas de gelifração mais intensa.

Segundo CLAPPERTON (1993), as concentrações de blocos e matacões dos pequenos vales de primeira ordem do planalto do Itatiaia (MODENESI, 1992; MODENESI-GAUTTIERI \& TOLEDO, 1996) são muito semelhantes aos stone streams das Ilhas Falklands e de outras áreas submetidas à atividade periglacial quaternária. As características desses depósitos e a localização, tamanho e abundância dos matacões sugerem ação combinada de processos gravitacionais (rockfall) - com provável interferência de sismicidade - e processos de clima frio e úmido (frost weathering), particularmente eficientes na liberação de detritos grossos (MODENESI, 1992).

\section{CARACTERÍSTICAS CLIMÁTICAS DOS PLANALTOS DE CAMPOS DO JORDÃO E ITATIAIA}

As cimeiras da Mantiqueira têm um regime climático particular, resultado da altitude e de sua localização nos trópicos úmidos, na margem oriental do continente sul-americano. Sob controle do sistema tropical atlântico, essa área é atingida com freqüência e intensidade variáveis pelo sistema polar, sendo ainda influenciada pelos alísios de sudeste (fig. 1). O papel da altitude é importante no abaixamento das temperaturas e na intensificação das chuvas. Os valores médios anuais disponíveis de temperatura são de aproximadamente $11,5^{\circ} \mathrm{C}$ nos setores mais elevados do Itatiaia e de $14,3^{\circ} \mathrm{C}$ em Campos do Jordão. A pluviosidade é, respectivamente, $2.400 \mathrm{~mm}$ e $1.800 \mathrm{~mm}$.

\subsection{Itatiaia}

Para definir as características climáticas predominantes no planalto do Itatiaia foram avaliados os dados anuais e mensais da estação meteorológica Alto do Itatiaia $\left(22^{\circ} 25^{\prime} \mathrm{S} / 44^{\circ} 50^{\prime} \mathrm{W}\right)$, localizada a $2.199 \mathrm{~m}$ de altitude, em operação de janeiro de 1923 a setembro de 1951.

A precipitação pluviométrica anual varia de 1.967 a $3.037 \mathrm{~mm}$, concentrada na primavera-verão (83\%). A média do mês mais chuvoso, janeiro, é $429 \mathrm{~mm}$ ( $18 \%$ do volume) e do mês mais seco, julho, é $35 \mathrm{~mm}$. O maior número de dias chuvosos ocorre no verão $(23,6$ dias); a média mais baixa é registrada no inverno (7,5 dias). A maior variação interanual ocorre em agosto $(101,8 \%)$ e a menor, em dezembro. Entretanto, é importante salientar que a diminuição da pluviosidade - significativa apenas nos 3 meses mais frios (junho, julho e agosto) - não é suficiente para definir uma estação seca (fig. 6).

\begin{tabular}{|c|c|c|c|c|c|c|c|c|c|c|c|c|}
\hline & Postos & $\begin{array}{l}\text { CHUVA } \\
\text { TOTAL } \\
\text { (MBM) }\end{array}$ & MAX. & Min. & $\begin{array}{l}\text { Desvio } \\
\text { (CV) }\end{array}$ & $\begin{array}{c}\text { SAZONAL } \\
\begin{array}{c}\text { PruMaV. } \\
\text { VERÁO }\end{array}\end{array}$ & $\begin{array}{l}\text { MÊs mats } \\
\text { CHUVOSO } \\
\text { (Ma) }\end{array}$ & $\begin{array}{l}\text { MEs menos } \\
\text { CHuvoso } \\
\text { (MM) }\end{array}$ & $\begin{array}{l}\text { Desvio } \\
\text { MAX. }\end{array}$ & $\begin{array}{c}\text { Nemédio dLAS } \\
\text { CHUVOSOS } \\
\text { POR ANO }\end{array}$ & $\max$. & Mıs. \\
\hline $\begin{array}{c}\text { ITATALIA } \\
\text { (1923-51) }\end{array}$ & $\begin{array}{l}\text { Alto do } \\
\text { Itatiaia }\end{array}$ & 2419 & $\begin{array}{c}3037 \\
(1947)\end{array}$ & $\begin{array}{c}1967 \\
(1928)\end{array}$ & $12 \%$ & $83 \%$ & $\operatorname{Jan}(428)$ & Jul (35) & $\begin{array}{c}\text { Ago } \\
(102 \%)\end{array}$ & 15 & 25 (Jan) & $\begin{array}{l}6 \\
\text { (Jun- } \\
\text { Ago) }\end{array}$ \\
\hline \multirow{3}{*}{$\begin{array}{c}\text { C. DO } \\
\text { JORDKO } \\
\text { (1972-97) }\end{array}$} & $\begin{array}{l}\text { Pico do } \\
\text { Itapeva }\end{array}$ & 2047 & $\begin{array}{c}2810 \\
(1973)\end{array}$ & $\begin{array}{c}1333 \\
(1964)\end{array}$ & $16 \%$ & $75 \%$ & $\begin{array}{l}\text { Jan (313); } \\
\text { Dez (312) }\end{array}$ & Jun (48) & $\begin{array}{c}\text { Jun } \\
\text { (89\%) }\end{array}$ & 16 & 24 (Jan) & $\begin{array}{l}9 \\
\text { (Jun- } \\
\text { Ago) }\end{array}$ \\
\hline & $\begin{array}{c}\text { Vila } \\
\text { Capivari }\end{array}$ & 1759 & $\begin{array}{l}2637 \\
\text { (1983) }\end{array}$ & $\begin{array}{c}1396 \\
(1975)\end{array}$ & $16 \%$ & $74 \%$ & $\begin{array}{c}\text { Jan e Dez } \\
\text { (280) }\end{array}$ & Ago (44) & $\begin{array}{l}\text { Ago } \\
(99 \%)\end{array}$ & 24 & 28 (Jan) & $\begin{array}{c}21 \\
\text { (Set) }\end{array}$ \\
\hline & INEMET & 1639 & $\begin{array}{c}2597 \\
(1983)\end{array}$ & $\begin{array}{c}1148 \\
(1997)\end{array}$ & $19 \%$ & $75 \%$ & $\operatorname{Jan}(275)$ & Ago (41) & $\begin{array}{c}\text { Ago } \\
(105 \%)\end{array}$ & 13 & 22 (Jan) & (Juil) \\
\hline
\end{tabular}

FIGURA 6 - Síntese da caracterização pluviométrica dos planaltos de Itatiaia e Campos do Jordão. 
Apesar de a amplitude térmica diária ser grande em climas de montanha, as amplitudes mensais e anuais são pequenas. Fevereiro e julho são, respectivamente, os meses mais quente e mais frio $\left(13,7\right.$ e $\left.8,4^{\circ} \mathrm{C}\right)$, sendo a diferença interanual maior nos meses mais frios. A máxima absoluta foi $24^{\circ} \mathrm{C}$ e a mínima, $-5^{\circ} \mathrm{C}$ (fig. 7).

\begin{tabular}{|c|c|c|c|c|c|c|}
\hline & Postos & $\begin{array}{l}\text { TEMP } \\
\text { MÉmD } \\
\text { ANuAL } \\
\text { ANC) }\end{array}$ & $\begin{array}{c}\text { Mes } \\
\begin{array}{c}+ \\
\text { QuENTE } \\
\left({ }^{\circ} \mathrm{C}\right)\end{array}\end{array}$ & $\begin{array}{c}\text { Mes } \\
\dot{+} \\
\text { FRIO } \\
\left.{ }^{\circ} \mathrm{C}\right)\end{array}$ & $\begin{array}{l}\text { Max. } \\
\text { Hist. } \\
\text { DiARA } \\
\left({ }^{\circ} \mathrm{C}\right)\end{array}$ & $\begin{array}{c}\text { MiN. } \\
\text { HIST. } \\
\text { DIÁRIA } \\
\left.{ }^{\circ} \mathrm{C}\right)\end{array}$ \\
\hline $\begin{array}{c}\text { ITATIAIA } \\
(1923-51)\end{array}$ & $\begin{array}{l}\text { Alto do } \\
\text { ltatlaia }\end{array}$ & 11,5 & $\begin{array}{c}\mathrm{Fev} \\
(13,7)\end{array}$ & $\begin{array}{r}\text { Jul } \\
(8,4)\end{array}$ & 24,0 & $-5,0$ \\
\hline $\begin{array}{c}\text { C. Do } \\
\text { JoRDAl } \\
(1972-97)\end{array}$ & INEMET & 14,3 & $\begin{array}{c}\mathrm{Fev} \\
(17,7)\end{array}$ & $\begin{array}{l}\text { Jul } \\
(9,7)\end{array}$ & 32,6 & $-7,3$ \\
\hline
\end{tabular}

FIGURA 7 - Síntese da caracterização da temperatura dos planaltos de Itatiaia e Campos do Jordão.

Os valores mensais de umidade relativa são altos durante o ano inteiro, variando de $72 \%$ (agosto) a 89,2\% (dezembro).

Geadas são mais comuns em julho (27 registros em 29 anos), mas ocorrem, praticamente, em todos os meses, com exceção de janeiro e fevereiro; as maiores incidências desse fenômeno foram em 1938 e 1940, respectivamente 101 e 95 eventos. A ocorrência mínima foi de 18 dias de geada/ano, em 1925. No período analisado, $40 \%$ dos dias de inverno apresentaram geada (fig. 8)

No inverno, a freqüente queda da temperatura abaixo de $0^{\circ} \mathrm{C}$ pode formar, na superfície úmida do solo, cristais aciculares de gelo (needle ice) (fig. 9) e crostas de gelo em poças d'água. Nas vertentes sombrias, o congelamento da água nas camadas superficiais da rocha intemperizada contribui para a sua desagregação e fragmentação em grânulos e pequenos seixos angulares (MODENESI, 1992) (fig. 10).

\subsection{Campos do Jordão}

Situado pouco ao sul e pelo menos $500 \mathrm{~m}$ abaixo do planalto do Itatiaia, o planalto de Campos do Jordão também é área de acentuada individualização climática, com dinamismo atmosférico complexo, caracterizado pela atuação dos sistemas equatorial, tropical e polar (MONTEIRO, 1973; CONTI, 1975), sobre um relevo de altitude considerável e compartimentação variada. A maior extensão do planalto e a incisão profunda dos vales subseqüentes têm influência na distribuição das chuvas (MODENESI, 1988).

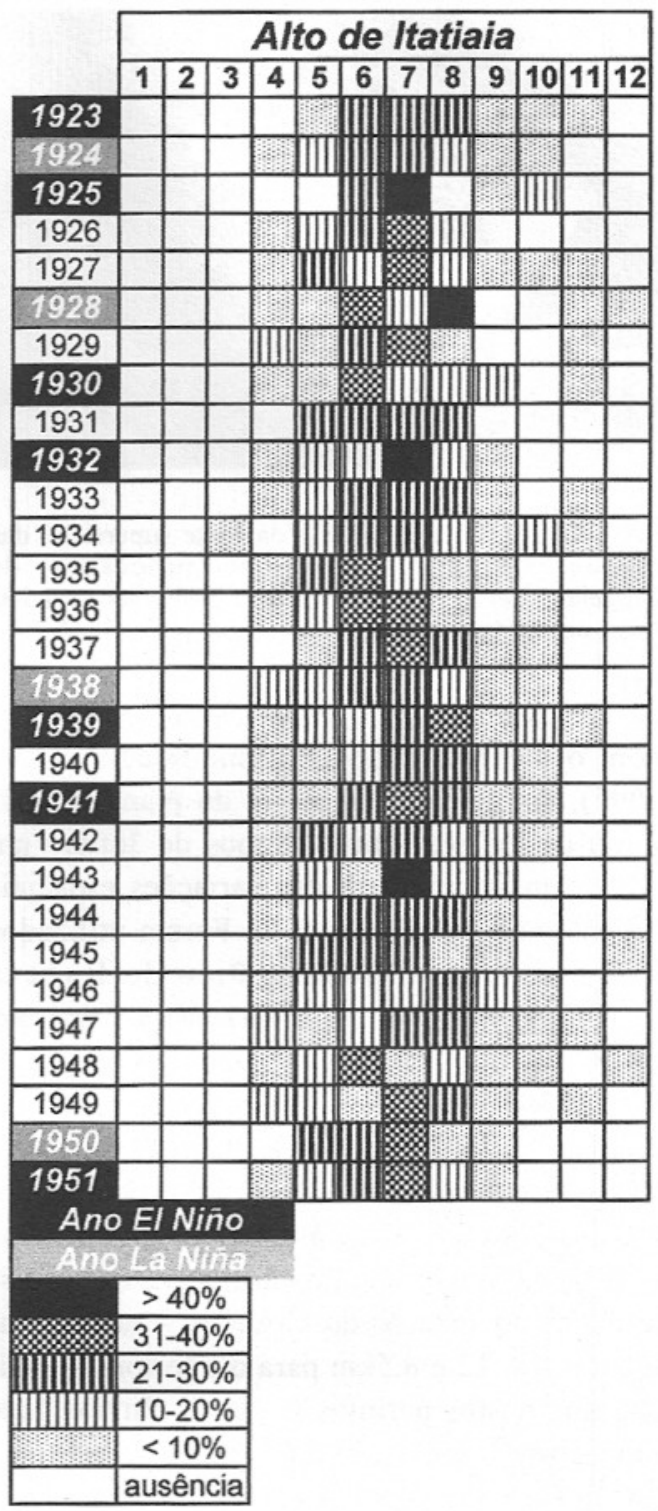

FIGURA 8 - Variação porcentual mensal das geadas no planalto de Itatiaia.

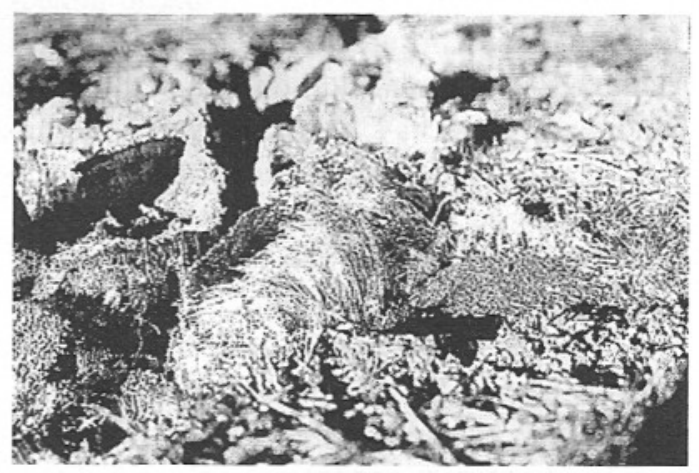

FIGURA 9 - Cristais aciculares de gelo (needle ice), com altura aproximada de $1 \mathrm{~cm}$, formados na superfície úmida dos solos das várzeas do planalto de Itatiaia. 


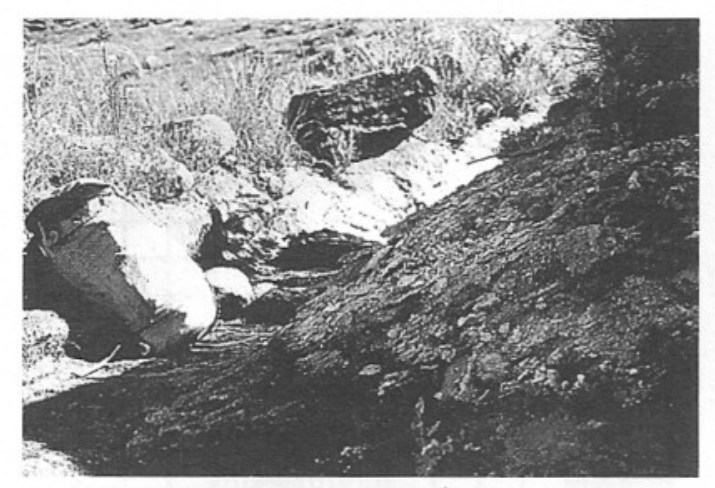

FIGURA 10 - Fragmentação da parte superficial das rochas intemperizadas, por processos de congelamento e degelo; fenômeno observado nos dias frios, nas vertentes sombrias do planalto do Iatiaia.

A existência de postos pluviométricos com o mesmo período de medição (1972 1997), em diferentes setores do planalto, permitiu estabelecer para Campos do Jordão um quadro mais completo das variações espaciais e temporais da pluviosidade. Foram utilizados dados de quatro postos: Pico do Itapeva $\left(22^{\circ} 46^{\prime} \mathrm{S} / 45^{\circ} 31^{\prime} \mathrm{W}, 1.840 \mathrm{~m}\right)$, Vila Capivari $\left(22^{\circ} 42^{\prime} \mathrm{S} / 45^{\circ} 34^{\prime} \mathrm{W}, 1.600 \mathrm{~m}\right)$, Marmelos $\left(22^{\circ} 37^{\prime} \mathrm{S} / 45^{\circ} 29^{\prime} \mathrm{W}, 1.040 \mathrm{~m}\right)$ e Campos do Jordão INEMET $\left(22^{\circ} 44^{\prime} \mathrm{S} / 45^{\circ} 35^{\prime} \mathrm{W}, 1.579 \mathrm{~m}\right)$; o primeiro, situado na borda sudeste do planalto, e os outros, nos vales subseqüentes dos ribeirões Capivari e dos Marmelos e nas proximidades do Palácio do Governo - respectivamente, a 8,12 e $8,5 \mathrm{~km}$ para o interior. A posição dos postos permite avaliar a pluviosidade num corte transversal do planalto, paralelo à penetração dos ventos de leste, principais responsáveis pelas chuvas da região (MONTEIRO, 1964; 1973; CONTI, 1975).

Condições regionais da circulação atmosférica determinam um ritmo climático semelhante em todo o planalto, ou seja, a distribuição mensal dos totais pluviais segue o mesmo padrão nos quatro postos, com concentração aproximada de $75 \%$ na primavera-verão (outubro a março). Dezembro e janeiro são os meses mais chuvosos (fig. 6), com totais semelhantes. Junho, julho e agosto revezam-se como os meses de estiagem e maior variação interanual. No período analisado, todos os postos apresentam seqüências de até 6 meses com pluviosidade inferior a $5 \%$. Entretanto, o número de anos com meses seguidos com precipitação inferior a $2 \%$ aumenta de 9 no
Itapeva para 13 em Vila Capivari, 14 no INEMET e 15 no ribeirão dos Marmelos, indicando diminuição das condições de umidade para o interior do planalto. Esta diminuição é mais nítida no período 1959/1976, analisado anteriormente por MODENESI \& NUNES (1998) e caracterizado por maior interferência de eventos ENOS. A ocorrência de mais de 2 meses consecutivos com precipitação inferior a $2 \%$ é rara na borda sudeste do planalto; para o interior é mais freqüente e, em alguns anos, pode chegar até 6 meses.

Variações locais do relevo explicam diferenças nos totais anuais de chuva. Pico do Itapeva, na borda sudeste do planalto, registra totais muito superiores aos dos postos do interior, assim como a maior amplitude anual do período (2.810 - $1.330 \mathrm{~mm})$. Pico do Itapeva e Vila Capivari apresentam valores de coeficiente de variação semelhantes, enquanto no posto do INEMET os valores são maiores. Note-se, porém, que Vila Capivari registra o maior número de dias de chuva e Marmelos, o menor (fig. 6).

As temperaturas referidas para o planalto de Campos do Jordão (1972 - 1995) são da estação INEMET, a única com medição deste parâmetro. Em termos médios, fevereiro e janeiro são os meses mais quentes (respectivamente 17,7 e $17,5^{\circ} \mathrm{C}$ ) e julho, o mais frio $\left(9,7^{\circ} \mathrm{C}\right)$. A maior variação interanual ocorre no outono-inverno. A máxima registrada é de $32,6^{\circ} \mathrm{C}$ e a mínima, de $-7,3^{\circ} \mathrm{C}$. Análise anterior (MODENESI, 1988) dos dados de Vila Capivari para período menor (1973 - 1978) registra temperatura média de $13,6^{\circ} \mathrm{C}$, média do mês mais quente (janeiro) $16,8^{\circ} \mathrm{C}$, máxima de $29,9^{\circ} \mathrm{C}$ e mínima de $-3,8^{\circ} \mathrm{C}$.

Temperaturas abaixo de zero e geadas são fenômenos comuns. Dados de 40 anos de observações (1937 - 1976) em Vila Capivari mostram que $90 \%$ dos dias de geada (média de 46 dias/ano) ocorrem de maio a agosto, com maior incidência, pela ordem, em julho, agosto e junho; 23 anos apresentam mais de 30 dias de geada/ano, com máximo de 70 dias/ano (1968) e mínimo de 9 dias/ano (fig. 11). No período analisado não há registro de neve, mas nevadas esporádicas têm sido referidas (SEGADAS-VIANA \& DAU, 1965; MODENESI, 1992) 


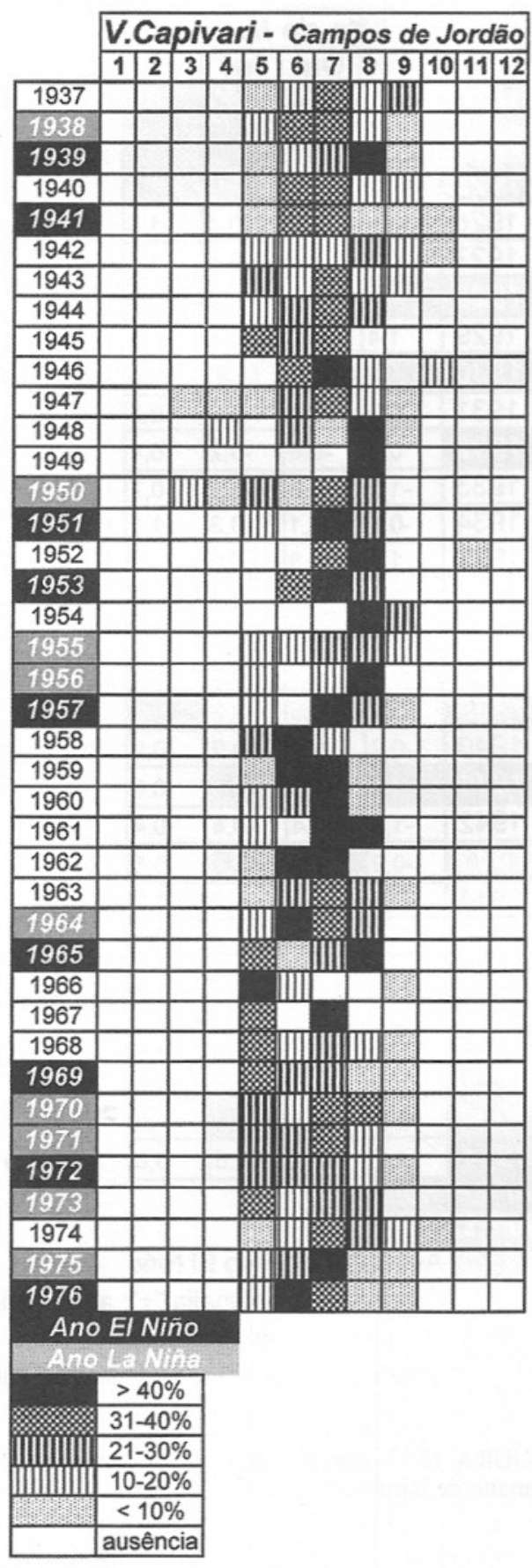

FIGURA 11 - Variação porcentual mensal das geadas no planalto de Campos do Jordão.

A umidade relativa (Estação Meteorológica Campos do Jordão, D2 - 096, 1974-1993) é alta durante todo o ano, variando de $82,3 \%$ (setembro) a $88,6 \%$ (dezembro).

Como observado anteriormente, variações da altitude e da orientação das vertentes introduzem modificações locais no clima do planalto de Campos do Jordão. Na borda sudeste há diminui- ção da temperatura, freqüente formação de nevoeiros e aumento da pluviosidade; para o interior, em direção ao Sul de Minas, caracteriza-se uma estação mais seca, marcada pelo aparecimento de algumas espécies de cerrado em meio aos campos (MODENESI, 1988).

A análise climática dos dois planaltos mostra que, apesar de a distribuição das chuvas durante o ano ser desigual, com concentração expressiva na primavera-verão, a umidade disponível é sempre elevada, mesmo nos meses menos úmidos. Este fato e a maior variação interanual nos meses mais frios - com aparecimento de anos com invernos muito úmidos - explicariam a grande incidência de geadas e, eventualmente, de neve.

A maior altitude do planalto de Itatiaia determina valores invariavelmente mais baixos da temperatura média anual, das médias mensais dos meses mais quente e mais frio e das máximas absolutas; entretanto, a mínima absoluta $\left(-5^{\circ} \mathrm{C}\right)$ é superior à de Campos do Jordão $\left(-7,3^{\circ} \mathrm{C}\right)$, o que contraria as informações anteriores e deixa dúvidas quanto à sua precisão.

\section{A INFLUÊNCIA DO EL NIÑO OSCILAÇÃO SUL NA VARIABILIDADE CLIMÁTICA}

Nas últimas décadas tem sido demonstrado que o fenômeno ENOS, em sua fase quente, altera o padrão climático de várias regiões da América do Sul, ainda que de forma diferenciada quanto à sua magnitude e período de manifestação.

Regiões de forte precipitação ou anomalias de temperatura têm sido associadas a valores extremos, negativos ou positivos, da Oscilação Sul (KILADIS \& DIAZ, 1989). A influência da fase quente do El Niño no aumento da chuva e temperatura do sudeste e sul do país foi demonstrada por vários autores (CHU, 1991; SUGAHARA, 1991; ABREU et al., 1993; XAVIER et al., 1995; NUNES, 1997, entre outros).

Ao avaliar o impacto do ENOS na pluviosidade global, ROPELEWSKI \& HALPERT (1987) constataram que, em relação a sua região de origem no Pacífico tropical, o fenômeno afeta tardiamente a parte tropical atlântica da América do Sul. A extrema complexidade desse fenômeno de interação atmosfera-oceano implica, ainda, diferenças consideráveis entre eventos. O impac- 
to do ENOS é mais evidente nas ocorrências particularmente fortes, especialmente da sua fase quente, quando há nítido aumento da pluviosidade no sudeste e sul do Brasil.

Para o Estado de São Paulo, esse fato foi comprovado por NUNES (1997). A eventual interferência do ENOS nas cimeiras da Mantiqueira foi avaliada pela análise, em nível sazonal, dos valores excepcionais de chuva para os quatro postos de Campos do Jordão e para Itatiaia, de modo a destacar os períodos do ano mais sensíveis à sua influência. A escolha dos anos ENOS segue a proposta de ROPELEWSKI \& HALPERT (1987). O grau de desvio da chuva em relação ao período histórico analisado foi obtido pela padronização dos dados:

$$
\begin{gathered}
\mathrm{z}=(\mathrm{Xi}-\mathrm{MA}) / \mathrm{s} \\
\mathrm{z}=\text { valor do desvio } \\
\mathrm{Xi}=\text { cada valor da série } \\
\mathrm{MA}=\text { média aritmética do período } \\
\mathrm{s}=\text { desvio padrão do período }
\end{gathered}
$$

Valores entre 1,0 e -1,0 são considerados habituais.

No Itatiaia (1923-1951), 45\% dos anos registram ocorrência do ENOS, sendo 8 anos de El Niño e 5, de La Niña, sem nenhuma influência marcante; valores excepcionais positivos e negativos ocorrem indistintamente em todo o período (fig. 12).

Em Campos do Jordão, 35\% dos 26 anos avaliados (1972-1997) registram eventos El Niño (6) ou La Niña (4). O exame das anomalias (fig. 13) reforça as diferenças entre os postos, visto que as excepcionalidades positivas e/ou negativas nem sempre foram concomitantes. Em todos os postos, os valores mais altos de desvio positivo $(>2,0)$ ocorrem sempre em anos ENOS. Não há um padrão sazonal marcante, mas anomalias positivas, ou tendência a valores acima dos habituais, podem ocorrer no período menos chuvoso (outono-inverno). O ano de 1972 constitui a única exceção, com registro de anomalia negativa em Marmelos. Anos La Niña apresentam tendência a chuvas abaixo do normal no inverno (fig. 13).

Dados de Vila Capivari para o período 1956 1990 evidenciam nitidamente a influência do El Niño no aumento das chuvas de outono e inver-

\begin{tabular}{|c|c|c|c|c|}
\hline & \multicolumn{3}{|c|}{ Alto do Itatiaia } & \\
\hline & Ver & Out & Inv & Pri \\
\hline 1923 & 0,3 & 要 & 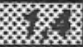 & 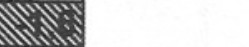 \\
\hline 1924 & 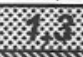 & 1 & i. & 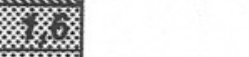 \\
\hline 1925 & MN & 1,0 & 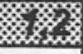 & 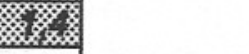 \\
\hline 1926 & 0,3 & 2,7 & 0,4 & 1,5 \\
\hline 1927 & 0,2 & 1,7 & 0,7 & $-1,4$ \\
\hline 1928 & W. & 0,2 & 0,0 & W. \\
\hline 1929 & 1,4 & 0,1 & 0,4 & $-0,9$ \\
\hline 1930 & (n) & 0,3 & 0,9 & 0,5 \\
\hline 1931 & 0,2 & $-0,6$ & $-0,8$ & 0,2 \\
\hline 1932 & 0,3 & $-0,6$ & $-0,2$ & $-0,4$ \\
\hline 1933 & $-1,5$ & 0,3 & 0,1 & 0,7 \\
\hline 1934 & $-0,1$ & $-1,1$ & $-0,3$ & $-1,3$ \\
\hline 1935 & 1,1 & 0,8 & 0,6 & $-1,2$ \\
\hline 1936 & 0,1 & $-1,3$ & 0,5 & $-1,3$ \\
\hline 1937 & $-0,7$ & 0,5 & $-1,8$ & 1,6 \\
\hline 1938 & $-0,5$ & 0,1 & 0,6 & 0,5 \\
\hline 1939 & $-0,2$ & $-0,5$ & $-0,3$ & W. \\
\hline 1940 & $-0,2$ & $-1,4$ & $-0,2$ & $-0,9$ \\
\hline 1941 & Nav & $-1,0$ & 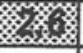 & 0,0 \\
\hline 1942 & $-1,0$ & $-0,4$ & $-0,4$ & 0,4 \\
\hline 1945 & $-0,2$ & $M$ & 47 & $-0,5$ \\
\hline 1944 & $-0,5$ & 0,3 & $-1,2$ & 1,3 \\
\hline 1945 & 1,7 & 1,2 & $-0,2$ & 0,5 \\
\hline 1946 & $-0,6$ & $-0,1$ & $-0,6$ & 0,8 \\
\hline 1947 & 2,5 & $-0,9$ & 1,9 & $-0,4$ \\
\hline 1948 & $-0,6$ & $-1,0$ & $-0,4$ & 0,3 \\
\hline 1949 & 0,4 & $-0,7$ & $-0,9$ & $-0,2$ \\
\hline 1950 & 0,6 & 1,0 & N.W & 1,0 \\
\hline 1951 & 1,0 & $-0,3$ & $-0,5$ & 0,0 \\
\hline $\begin{array}{l}\text { Ano EI } \\
\text { Ano La }\end{array}$ & Niño & & & \\
\hline Ano La & $\begin{array}{l}\text { Whina } \\
\text { Anoma }\end{array}$ & $a "+$ & ano $E$ & Niño \\
\hline & $\begin{array}{l}\text { Tendê } \\
\text { Anome } \\
\text { Tendê }\end{array}$ & ia a & no & $\begin{array}{l}\text { "+": ano EI Niño } \\
\text { Viña } \\
\text { "-": ano La Niña }\end{array}$ \\
\hline
\end{tabular}
no (MODENESI \& NUNES, 1998). Esse padrão coincide com o reconhecido por NUNES (1997) para o mesmo período, em todo o Estado de São Paulo.
FIGURA 12 - Anomalia sazonal da pluviosidade no planalto de Itatiaia.

Quanto à atuação do ENOS em periodos pretéritos, dados paleoambientais mostram que ritmos climáticos semelhantes aos padrões atuais do El Niño - porém dotados de valores diferentes, com maior duração - desenvolveramse na América do Sul durante os últimos 5.000 anos, com freqüente alternância das fases El Niño e La Niña (MC GLONE, et al., 1992). Este fato explicaria, por exemplo, perturbações observadas em período de séculos ao longo da costa do Equador (BOGIN, 1982) e, em períodos maiores, no Peru (ORTLIEB et al., 1989). 


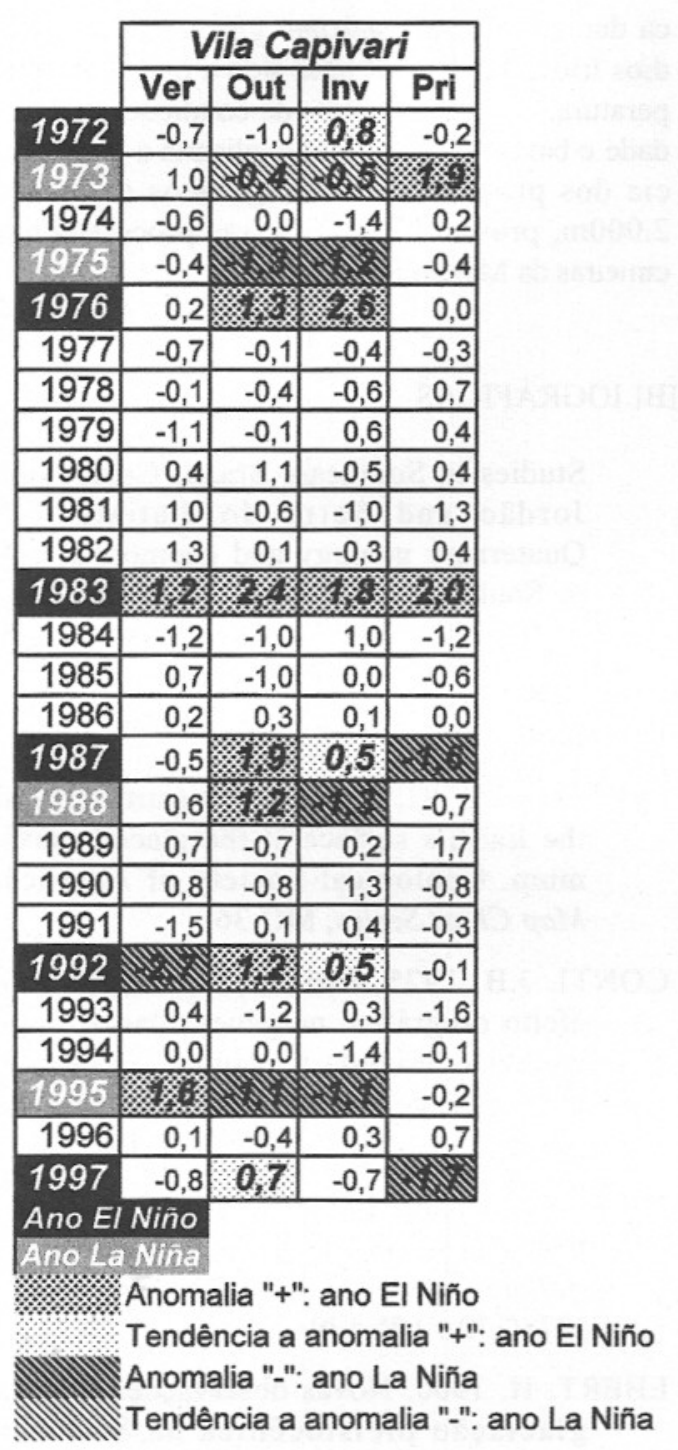

FIGURA 13 - Anomalia sazonal da pluviosidade no planalto de Campos do Jordão.

Na costa sul e sudeste do Brasil, a permanência de condições semelhantes às do El Niño por décadas ou séculos teria produzido perturbações no regime das chuvas e ventos e, conseqüentemente, em alguns mecanismos naturais (MARTIN et al., 1991).

\section{VARIAÇÕES CLIMÁTICAS E PROCESSOS GEOCRIOGÊNICOS QUATERNÁRIOS NAS CIMEIRAS DA MANTIQUEIRA}

As cimeiras da Mantiqueira apresentam características climáticas particulares, relacionadas à altitude e à sua posição frontal na fachada atlântica da América do Sul. A alternância de cli- mas quaternários úmidos e secos, bem marcada nos compartimentos interplanálticos deprimidos, como o Vale do Paraíba, é menos nítida em Campos do Jordão e mais complexa nos altos do Itatiaia.

A partir do fim do Pleistoceno, a diminuição da atividade morfodinâmica e mudança dos processos geomórficos atuantes nas baixas vertentes, dos dois planaltos, indicam condições ambientais mais constantemente úmidas no Itatiaia, onde climas mais úmidos teriam ocorrido sem interrupção, pelo menos nos últimos 8.500 anos. Em Campos do Jordão, pequenas variações intraholocênicas, com alternância de condições subtropicais de altitude - ora úmidas e quentes, ora relativamente mais secas e frias -, teriam acompanhado, ainda que de forma atenuada, o ritmo das flutuações climáticas quaternárias dos compartimentos interplanálticos.

A análise do clima atual dos planaltos de Itatiaia e Campos do Jordão demonstra que eventos do tipo El Niño não têm nenhuma influência marcante no regime de chuvas do Itatiaia, mas que, em Campos do Jordão, os anos de influência do El Niño são caracterizados por anomalias positivas ou tendência a valores acima dos habituais. Estas observações parecem concordar com as evidências paleoclimáticas regionais, melhor consolidadas.

No Itatiaia, mais elevado e isolado - sob impacto direto de massas de ar úmido de diferentes origens -, teria prevalecido a influência da altitude e da posição geográfica. Eventuais interferências de eventos tipo El Niño não teriam produzido, como não produzem hoje, alterações significativas na distribuição das chuvas. Ou seja, as condições de umidade teriam sido contínuas. Nas fases frias do Pleistoceno e em episódios holocênicos menores, a queda de temperatura representaria a principal variação climática. Como observado anteriormente (MODENESI, 1992), este frio mais intenso teria sido suficiente para provocar nevadas abundantes, mesmo sob um ritmo climático semelhante ao atual. Estação seca curta e mal definida (diminuição significativa das chuvas apenas nos três meses mais frios) e ocorrência freqüente de geadas e temperaturas abaixo de zero em períodos maiores (respectivamente, 8 ou 9 meses e 5 a 7 meses) possibilitariam nevadas abundantes no Itatiaia, sem necessidade de inversão no regime das chuvas.

Em Campos do Jordão, onde a atual influência do El Niño provoca aumento das chuvas no outono-inverno, há evidências paleoambientais de ciclicidade, com pequena variação das condições 
de umidade. Disso se deduz que os climas do Pleistoceno Superior e do Holoceno teriam se sucedido em seqüências semelhantes àquelas das terras baixas adjacentes, porém com contrastes menos marcados.

No planalto do Itatiaia, sob condições contínuas de umidade, a principal modificação climáti- ca durante o último máximo glacial e em episódios frios holocênicos teria sido a queda da temperatura. A concomitância de condições de umidade e baixas temperaturas explicaria a importância dos processos geocriogênicos acima de $2.000 \mathrm{~m}$, provável limiar desses processos nas cimeiras da Mantiqueira.

\section{REFERÊNCIAS BIBLIOGRÁFICAS}

ABREU, M.L.; ROCHA, A.M.G.C.; BRITO, I.J. 1993. Efeito do El Ninõ 1991/1992 na variação das médias climatológicas de inverno no campo da temperatura na região sudeste do Brasil. Rio Claro: Boletim de Geografia Teorética, 23 (45/46): 49-53.

AB'SABER, A.N. 1969. O domínio morfoclimático dos mares de morros no Brasil. São Paulo: Instituto de Geografia - USP, Geomorfologia (2), 9 p.

\& BERNARDES, N. 1958. Vale do Paraíba, Serra da Mantiqueira e arredores de São Paulo. In: CONGRESSO INTERNACIONAL DE GEOGRAFIA, XVIII, Rio de Janeiro. Guia de Excursões (4). Rio de Janeiro, Conselho Nacional de Geografia, 304 p. (Editado em francês e inglês em 1956).

ALMEIDA, F.F.M. de. 1976. The System of Continental Rifts bordering the Santos Basin, Brazil. In: CONTINENTAL MARGINS OF ATLANTIC TYPE, SÃO PAULO, 1975. Anais da Academia Brasileira de Ciências, Rio de Janeiro, 48 Suplemento, p. 15-26.

BOGIN, B. 1982. Climate change and human behaviour on the southwest coast of Ecuador. Central Issues in Anthropology, 4 (1): $25-50$

BROCHU, M. 1957. Occurrence possible de glaciations locales pléistocène et de phénomènes periglaciaires au Brésil. Berlin: Zeitschrift für Geomorphologie, 1 (3): 271-276.

CHU, P.S. 1991. Brazil's climate anomalies and El Ninõ. In: GLANTZ, M. H. et al. Teleconnections linkings worldwide climate. Cambridge: Cambridge University Press, págs. 43-71.

CLAPPERTON, C.M. 1993. Quaternary of the South American Highlands, Part II: Case
Studies in Southeast Brazil: Campos do Jordão and Serra do Itatiaia. In: Quaternary geology and geomorphology of South America. Amsterdam: Elsevier, p. 243-258.

CLIMAP 1976. The surface of the Ice-Age Earth. Science, 191 (4.232): 1.131-1.137.

1981. Seasonal reconstructions of the Earth's surface at the glacial maximum. Geological Society of America. Map Chart Series, MC-36.

CONTI, J.B. 1975. Circulação secundária e efeito orográfico na gênese das chuvas na região lesnordeste paulista. São Paulo, Universidade, Instituto de Geografia. 82 p. (Série Teses e Monografias, 18).

DE MARTONNE, E. 1940. Problèmes morphologiques du Brésil tropical atlantique. Annales de Géographie, 49 (277): 1-27 e (278/279): 106-129.

EBERT, H. 1960. Novas observações sobre a glaciação pleistocênica na Serra do Itatiaia. Rio de Janeiro: Anais da Academia Brasileira de Ciências , 32 (1): 51-73.

KILADIS, O.N. \& DIAZ, H.F. 1989. Global climatic anomalies associated with extremes in the Southern Oscillation. Journal of Climate, 2: 1.069-1.090.

LEHMAN, H. 1960. Observações morfoclimáticas na Serra da Mantiqueira e no Vale do Paraíba. Campinas: Notícia Geomorfoló-gica, 3 (5): 1-6.

MACAR, P. 1957. Note sur I'excursion a I'Itatiaia (Brésil, 1956). Berlin: Zeitschrift für Geomorphologie, 1 (3): 293-296.

MARTIN, L.; FLEXOR, J.M.; SUGUIO, K. 1991. Possible changes in the Holocene wind pattern recorded on Southeastern 
Brazilian coast. São Paulo: Boletim do Instituto de Geocências. - USP, 8: 117-131.

MC GLONE, M.S.; KERSHAW, A.P. \& MARKGRAF, V. 1992. E1 Niño/Southern Oscillation climatic variability in Australasian and South American paleoenvironmental records. In: H.F. DIAZ \& V. MARKGRAF, eds. El Niño - Historical and Paleoclimatic Aspects of the Southern Oscillation. Cambridge: Cambridge University Press, p. 435-462.

MODENESI, M.C. 1983. Weathering and morphogenesis in a tropical plateau. Braunschweig: Catena, 10 (3): 237-251.

1988. Significado dos depósitos correlativos quaternários em Campos do Jordão - São Paulo: implicações paleoclimáticas e paleoecológicas. São Paulo: Instituto Geológico, 155 p. (Boletim 7).

1989. Hillslope forms and Quaternary deposits in the Itatiaia plateau - RJ - Brazil. In: INTERNATIONAL SYMPOSIUM ON GLOBAL CHANGES IN SOUTH AMERICA DURING THE QUATERNARY, São Paulo. Special Publication, 1, São Paulo, p. 293-300.

1992. Depósitos de vertente e evolução quaternária do Planalto do Itatiaia. São Paulo: Revista do Instituto Geológico, 13 (1): 31-46.

MODENESI, M.C. \& MELHEM, T.S. 1986. Primeiros resultados da palinologia dos sedimentos turfosos da várzea do ribeirão das Flores, Itatiaia - RJ. São Paulo: Revista do Instituto Geológico, 7(1/2): 35-38.

1992. Palynological data on a Holocene peat deposit in tropical Brazil: preliminary paleoclimatic and paleoecological interpretations. São Paulo: Revista do Instituto Geológico, 13 (2): 7-15.

MODENESI-GAUTTIERI, M.C. \& TOLEDO, M.C.M. 1996. Weathering and the formation of hillslope deposits in the tropical highlands of Itatiaia - southeastern Brazil. Amsterdam: Catena, 27: 81-103.

MODENESI-GAUTTIERI, M.C. \& NUNES, L.H. 1998. Processos geocriogênicos quaternários nas terras altas do sudeste do Brasil: considerações climáticas.
Florianópolis: Geosul - Revista do Departamento de Geociencias - CFH, (14) 27: 391-393.

MONTEIRO, C.A.F. 1964. Sobre um índice de participação das massas de ar e suas possibilidades de aplicação à classificação climática. Rio de Janeiro: Revista Geográfica, 33 (61): 59-69.

1973. A dinâmica climática e as chuvas no Estado de São Paulo (estudo geográfico sob a forma de atlas). São Paulo: Instituto de Geografia - USP.

NUNES, L.H. 1997. Distribuição espaço-temporal da pluviosidade no Estado de São Paulo: variabilidade, tendências, processos intervenientes. São Paulo. Tese de Doutoramento, Escola Politécnica - USP, $192 \mathrm{p}$.

ORTLIEB, L.; MACHARÉ, J.; FOURNIER, M.; WOODMAN, P. 1989. Late Holocene beach ridge sequences in northern Peru: did they register the strongest paleo El Niños? In: INTERNATIONAL SYMPOSIUM ON GLOBAL CHANGES IN SOUTH AMERICA DURING THE QUARTENARY. Special Publication, 1: Program, Abstracts and General Information. São Paulo, ABEQUA/INQUA, p. 206-209.

PENALVA, F. 1967. Geologia e tectônica da região do Itatiaia (Sudeste do Brasil). São Paulo, Universidade, FFCL, p. 95196 (Boletim, 302 - Geologia 22).

RAYNAL, R. 1957. Les formations des versant et I'evolution climatique dans la Serra da Mantiqueira. Berlin: Zeitschrift für Geomorphologie, 1 (3): 279-289.

RICCOMINI, C. 1989. O Rift Continental do Sudeste do Brasil. Tese de Doutoramento, Instituto de Geociências - USP, $256 \mathrm{p}$.

ROPELEWSKI, C.F. \& HALPERT, M.S. 1987. Global and regional scale associated with E1 Niño/Southern Oscillation. Monthly Weather Review, 115 (8): 1.6061.626.

SEGADAS VIANA, F. \& DAU, L. 1965. Ecology of the Itatiaia Range, Southeastern Brazil. Rio de Janeiro: Arquivos do Museu Nacional, 53: 7-53. 
SILVEIRA, J.D. 1942. Itatiaia. In: CONGRESSO BRASILEIRO DE GEOGRAFIA, IX, Rio de Janeiro. Anais, Rio de Janeiro, Conselho Nacional de Geografia, 2: 707-720.

SUGAHARA, S. 1991. Flutuações interanuais, sazonais e intra-sazonais da precipitação no Estado de São Paulo. São Paulo. Tese de Doutoramento, Instituto Astronômico e Geofísico - USP, 146 p.

XAVIER, T.M.B.S.; DIAS, M.A.F.S.; XAVIER, A.F.S. 1995. Impact of ENSO episodes on the autumn rainfall patterns near São Paulo, Brazil. International. Journal of Climatology, 15(5): 571-584.

Endereço das autoras:

May Christine Modenesi-Gauttieri e Lucí Hidalgo Nunes - Instituto Geológico - SMA, Av. Miguel Stéfano 3.900, CEP 04301-903, São Paulo, SP - Brasil. E-mails: modenesi@igeologico.sp.gov.br, luci@igeologico.sp.gov.br 